\title{
AS VIAS DO ULTRACONSERVADORISMO ENTRE 1935 E 1945: O JORNAL A ORDEM - RN
}

\author{
MARCELO FURLIN* \\ RAFAEL HENRIQUE COLAVITE DE AGUIAR**
}

\begin{abstract}
RESUMO
Este artigo tematizou a pesquisa documental realizada a partir do periódico potiguar denominado A Ordem, entre os anos de 1935 a 1945. O estudo investigou e compreendeu de que forma o jornal da então Diocese de Natal pôde tecer uma base de estudos sobre os eventos regionais, nacionais e internacionais do período, por meio de sua linguagem clara e de aspecto quase narrativo, típico de jornais locais. Para análise do conteúdo do jornal recorreu-se a autores que versam sobre laicidade, educação, ensino religioso, totalitarismo e aparelhos ideológicos, além de pesquisas e artigos anteriores sobre o mesmo documento. $\mathrm{O}$ jornal apresentou dentre seus diversos focos a aproximação ideológica entre católicos e integralistas, o teor anticomunista de seu discurso e a defesa do ensino religioso como ferramenta de proselitismo e combate ao comunismo. Os resultados foram as constatações de que a educação é utilizada para fins ideológicos pelas políticas públicas; dado o atraso regional e apesar da incongruência das doutrinas, católicos e integralistas encontraram um
\end{abstract}

* Doutor em Letras pela Universidade de São Paulo. Coordenador do Programa de Pós-graduação em Educação da Universidade Metodista de São Paulo - email: marcelo.furlin@metodista.br

** Mestre em Educação pela Universidade Metodista do Estado de São Paulo. Graduado em Ciências Sociais pelo Centro universitário Fundação Santo André - CUFSA. Especializações na área de sociologia da educação, professor da rede privada e autor de livros de ficção - email: rafa.colavite@ gmail.com 
caminho paralelo para se fortalecerem politicamente na região Nordeste, em especial no estado do Rio Grande do Norte.

Palavras-chave: ultraconservadorismo; A Ordem; história; educação; Brasil.

\section{INTRODUÇÃO}

O presente estudo trata da análise documental do periódico A Ordem, publicado pela então diocese de Natal (RN), entre sua fundação, em 1935, até o fim do Estado Novo Brasileiro, em 1945. Tal estudo é parte integrante da dissertação realizada na linha de pesquisa Formação de Educadores pelo Programa de Pós-graduação em Educação, da Universidade Metodista do Estado de São Paulo UMESP), cujo término se deu em setembro de $2018 .^{1}$

O jornal A Ordem, do Rio Grande do Norte, disponível no acervo da Biblioteca $\mathrm{Nacional}^{2}$, reúne um conjunto de características únicas que proporcionaram a realização da pesquisa documental. Em suma, o periódico ao longo dos anos selecionados pela investigação (1935 - 1945) apresenta notícias de diversas esferas de interesse. Primeiramente, enquanto jornal, alcançava a população de maneira única, uma vez que o rádio e a televisão não eram difundidos na região Nordeste. Contribuindo aos fatores já ditos, o equilíbrio social e suas relações de poder mantiveram-se inalterados desde o período colonial, promovendo um contexto claro em relação às forças conservadoras da região, como o cristianismo, bem como os seus contrates (seria contrastes?) socioeconômicos dentro da hierarquia social e política. Sendo assim, A Ordem era a única, se não a exclusiva fonte de informações sobre o mundo para uma grande quantidade de pessoas de Natal e seus arredores, constituindo-se no principal veículo formador de opinião.

\footnotetext{
1 AGUIAR, Rafael Henrique Colavite de. Brasil e a espiral histórica: A Ordem, educação e poder. 2018. 166 folhas. Dissertação (Mestrado em Educação)-Escola de Comunicação, Educação e Humanidades da Universidade Metodista de São Paulo, São Bernardo do Campo. 2018.

2 http://memoria.bn.br
} 
Em segundo lugar, a escolha deste tipo de documento se dá pela riqueza do discurso. De forma que o jornal não foi produzido com a intenção de tornar-se registro histórico; ele apresenta dada clareza no discurso que tange o narrativo, registrando o cotidiano sem escamotear ideologias. Contudo, a pesquisa não só levou em conta os discursos quase narrativos presentes n'A Ordem, como também se valeu de ampla base bibliográfica para a devida análise da fonte de informação, pois

[...] Muitos dos documentos por ela utilizados não foram produzidos com o propósito de fornecer informações com vistas à investigação social, o que possibilita muitos vieses. Exemplificando: documentos autobiográficos e artigos de jornais podem distorcer muitos pontos na tentativa de construir uma boa história. [...] A maioria dos documentos registram relatos verbais, não provendo informações sobre comportamentos não-verbais, que, às vezes, são imprescindíveis para se analisar o sentido de determinada fala. (GODOY, 1995. p. 22)

E, portanto, para garantir que o procedimento de análise de material fosse realizado com a lucidez que a pesquisa científica demanda, toda ela foi respaldada por autores que tratam tanto da história do $\mathrm{Brasil}^{3}$, quanto mundial $^{4}$, de educação e laicismo ${ }^{5}$, ideologias e seu processo de polarização ${ }^{6}$. Ainda, ideologicamente, o jornal traz consigo toda a visão de mundo referente à comunidade cristã católica da região, uma vez que este periódico foi o veículo oficial da Diocese de $\mathrm{Natal}^{7}$, como será esclarecido mais adiante.

Além, o recorte temporal da pesquisa engloba eventos de relevância local, nacional e internacional: o foco potiguar da Intentona Comunista, a transformação do governo constitucio-

\footnotetext{
Em especial, Boris Fausto e Edgar Carone.

Eric Hobsbawn, Helen Graham e Michael Howard.

Otaíza Romanelli, Roseli Fischmann e Luiz Antônio Cunha, Hannah Arendt, Pierre Bourdieu e Luís Althusser.

A Diocese de Natal torna-se Arquidiocese apenas em 1952.
} 
nal de Getúlio Varga em Estado Novo Brasileiro e o palco de operações da Segunda Guerra Mundial, além de acompanhar a movimentação bélica e ideológica dos eventos europeus desde a Guerra Civil Espanhola, bem como os atritos entre o EIXO e o Vaticano. Logo, A Ordem retrata nas suas edições o processo de polarização ideológica vigente no mundo que possui amplos reflexos no Brasil e que, para tanto, oferece caminhos para o combate às ideologias de esquerda, em especial o comunismo, por intermédio do ensino religioso nas escolas.

Durante o andamento da macropesquisa que deu origem ao trabalho de dissertação foi criado um paralelo entre a década estudada representado pelo jornal e por eventos situados entre os anos de 2016 e 2018 na conjuntura brasileira que apontam para uma reincidência de tendências sociais, políticas e econômicas, cujas semelhanças podem ser identificadas no passado. O conceito de reincidência histórica segue um movimento em espiral ${ }^{8}$, cujo aprofundamento não cabe a este artigo, e que será tratado no futuro.

O presente artigo pretende tratar de alguns focos de análises realizados ao longo da pesquisa documental ${ }^{9}$, sendo estes: a aproximação improvável entre forças políticas conservadoras na região, como cristianismo e integralismo, bem como seu fortalecimento mútuo; o alcance proselitista da Ação Católica Brasileira e da Congregação Mariana de Moços, esta última responsável direta pela edição do jornal; o teor anticomunista do jornal, pautado especialmente em ataques constantes a esta ideologia política, que, apesar de existirem desde o século anterior, se reforçam graças à conjuntura mundial e nacional e, como tema

8 Pois não se pode admitir que o processo histórico seja linear, ou mesmo cíclico. Segundo vários filósofos, incluindo George Santayana, em 1905: "O progresso, longe de consistir em mudança, depende da capacidade de retenção. Quando a mudança é absoluta, não permanece coisa alguma a ser melhorada e nenhuma direção é estabelecida para um possível aperfeiçoamento; e quando a experiência não é retida, como acontece com os selvagens, a infância é perpétua. Aqueles que não conseguem lembrar o passado estão condenados a repeti-lo".

9 Os dados foram levantados de 3.020 edições d'A Ordem. De 14/07/1935 a $01 / 01 / 1946$. 
que comtempla os principais objetivos do jornal, a efetivação do ensino religioso enquanto disciplina na grade curricular brasileira, o que se tornara possível graças à aproximação ideológica com o governo Vargas.

\section{A ORDEM: UM BREVE HISTÓRICO}

Desde antes do período analisado, a cidade de Natal já se constituía uma das metrópoles regionais mais relevantes do Nordeste e uma das grandes marcas do estado do Rio Grande do Norte na história do nosso país; é a tendência conservadora enraizada no catolicismo. Porém, a origem do periódico se deve à revista de mesmo nome criada no Rio de Janeiro na década de 1920.

A revista tinha por objetivo principal a difusão do partidarismo católico, proselitismo propriamente dito, combatendo assim doutrinas religiosas diversas para garantir a hegemonia católica sobre as demais e, também, para reforçá-la no seio da população, já que desde o advento da República, no século anterior ao da pesquisa, a Igreja estava afastada do poder do Estado. A longo prazo as pressões populares, que culminariam em pressões políticas, seriam levadas para as esferas legislativas estaduais e nacionais, angariando vitórias para o ensino religioso, proselitista católico, nas escolas do país.

Dom Sebastião Leme, arcebispo do Rio de Janeiro, alia-se a Tristão de Ataíde ${ }^{10}$, diretor do Centro Dom Vital, e juntos unem-se na fundação da revista - as contribuições de ambos podem ser vistas no jornal norte-rio-grandense. A primeira vitória católica já se dá com a Constituição de 1934 que, indo de encontro com o Manifesto dos Pioneiros da Educação Nova, estabelece o Ensino Religioso no currículo nacional, aproximando a Ação Católica Brasileira e os ideais do governo Vargas, permitindo a chamada "restauração católica". Para tanto, a Congregação Mariana de Moços ${ }^{11}$ funda em 1935 na Diocese de Natal o jornal A Ordem.

\footnotetext{
Pseudônimo de Alceu Amoroso Lima.

11 A Congregação Mariana de Moços é um órgão fundado pelos jesuítas no século XVI com a finalidade de arregimentar militantes católicos de várias faixas etárias, voltando-se primordialmente a jovens e adultos. Seu braço fundado na Diocese de Natal, em 1932, tinha objetivos específicos relacionados às atividades de imprensa.
} 
Tristão de Athayde ressalta:

Pois as incongruências da imprensa agnostica levam, por vezes, a esses paradoxos [o de dirigir um jornal cujas ideias veiculadas não condizem com as próprias crenças pessoais], que repercutem dolorosamente na alma de um homem de consciência, e fazem um mal tremendo ao público. A culpa do surto "extremista" em nosso meio cabe, em grande parte, à imprensa. Foi ella que, pelos seus processos de sensação, pela inconsistencia de sua doutrinação, pela irresponsabilidade de suas affrontas levou o público a esse nervosismo, que se caracterisa justamente pela insatisfacção de tudo, pela vontade de mudar, pelo messianismo quotidiano. [...] (ATHAYDE, Tristão de. In: A ORDEM, 14/07/1935) ${ }^{12}$

A partir de então o jornal traçou linhas claras quanto à moral e bons costumes para a população da época; posicionou-se diante dos eventos internacionais, seguindo um padrão reconhecível e claro que estivesse de acordo com a doutrina católica e os eventos nacionais e mundiais: o do anticomunismo.

Falcão e Rebouças pontuam que

Nesse sentido, as representações que compõem o imaginário anticomunista engendrado pela Igreja católica no estado ganham forma prática no uso da imprensa como principal instrumento de combate ao inimigo vermelho. Ao mesmo tempo, é preciso levar em consideração que a utilização intensa de elementos simbólicos, formulando as significações conotativas em torno do inimigo, assumiu facetas diversas e ao mesmo tempo específicas, circunscritas de acordo com os interesses e as estratégias assumidas pela Santa Sé e pelo episcopado potiguar no combate ao que se denominou de "tempos despudorados". (FALCÃO e REBOUÇAS, 2013, p. 34)

12 A ortografia original do jornal será mantida, de forma a captar mais precisamente a linguagem e o idioma da época. 
Dessa forma, A Ordem se torna mais que um jornal que reúne as principais notícias regionais, nacionais e mundiais para a população de Natal e arredores. Nele encontra-se uma poderosa arma da cruzada católica anticomunista, cujas inspirações são muito anteriores à República Brasileira e oriundas de antigas tensões entre Igreja e classe trabalhadora na Europa do século XIX, agora intensificadas pela polarização ideológica derradeira na década estudada, 1935 - 1945, que culminaram inclusive nos eventos da Segunda Guerra Mundial. Cabe aqui lembrar que o combate ao comunismo pela Igreja se estende durante todo o século XX e início do XXI. Logo, A Ordem transcende a condição de veículo de comunicação para tornar-se um arcabouço ideológico ultraconservador, ferramenta e arma na mão de intelectuais e pseudointelectuais, católicos e integralistas.

Como medida para combater o momento considerado decadência da humanidade, e pela garantia da "civilização cristã" a partir do movimento de "restauração", Rio Grande do Norte é palco de fenômenos peculiares, improváveis em outras localidades do território nacional. Um desses fenômenos políticos é a aproximação que irá ocorrer entre a comunidade cristã potiguar e o integralismo.

Plínio Salgado (1935) defende que

A grande missão que este paiz tem o direito de exigir da imprensa nestes dias de confissão de valores, de desorientação doutrinária, de violentas manifestações de interesses de classes à cuja sombra agem apetites violentos dos exploradores de situação, a grande missão que cumpre os jornaes brasileiros é acima de tudo, - doutrinar.

Doutrinar a bôa doutrina, que é aquella que se origina da consideração superior dos acontecimentos [...]. Insistir diariamente, sem cansaço, sem enfado, sem desfallecimentos, na repetição de algumas verdades elementares que de ha muito se tornaram verdades pacificas para todos os que ainda conservam uma pequena dóse de bom senso e de sincero desejo de vêr crescer e desenvolver-se este grande povo, com a garantia da paz, da 
harmonização de todas as forças economicas e sociaes da Nação, num rumo de superior finalidade política. (SALGADO, Plínio In: $A$ ORDEM, 14 de julho de 1935)

A mera presença de artigos e notas escritas por integralistas notórios, como é o caso de Plínio Salgado, deixa claro que A Ordem - RN abrirá espaço para doutrinas e ideologias tradicionalistas, ultraconservadoras, correlacionadas ao catolicismo, neste caso, espacialmente (ou especialmente?) por serem anticomunistas. Quando o autor se evoca na insistência cotidiana de "verdades elementares", dogmáticas, tais atitudes refletem tanto a esfera religiosa quanto a ideológica política. Em outras palavras, os movimentos católico e integralista nesse local e época se utilizam dos mesmos mecanismos de fixação ideológica, ainda que pela ação da repetição, para garantir a manutenção da ordem social vigente.

\section{CATÓLICOS E INTEGRALISTAS N'A ORDEM: UMA UNIÃO ANTICOMUNISTA ${ }^{13}$}

\section{Como se deve combater - communismo \\ Uma conferencia do Pe. Helder Camara proferida em São Paulo sobre o assumplo}

Como dito anteriormente, o estado de Rio Grande do Norte reuniu diversos fatores que garantiram a manutenção de tendências conservadoras desde o período colonial até no mínimo a década 1935 - 1945, e sob muitos aspectos, até os dias de hoje, dificultando, por exemplo, a instauração das diretrizes da encíclica Rerum Novarum por muitos anos. Portanto, os interesses

13 Edição 496, de 09 de abril de 1937. Disponível em: http://memoria.bn.br/ DocReader/docreader.aspx?bib=764051\&pesq= Acesso em: 16/11/2018. 
de católicos e integralistas, apesar de paralelos se aproximavam dadas estas condições. Plínio Salgado e Miguel Reale, este não tanto quanto o primeiro, tinham seus artigos e notas replicados dos jornais católicos de Rio de Janeiro e São Paulo diretamente para A Ordem - RN, quando inclusive não escreviam diretamente ao leitor potiguar.

Uma das personagens icônicas da história brasileira recente, que custou a se desligar de seu passado vinculado ao integralismo, foi Dom Helder Câmara. Quatro vezes indicado ao prêmio Nobel da Paz, dado o seu posicionamento contra a Ditadura Militar no Brasil, e sumariamente sabotado das indicações pela mesma $^{14}$. Durante o período analisado pela pesquisa documental constatou-se que o clérigo representava uma ponte entre a Ação Católica Brasileira e a AIB, tanto no Nordeste quanto no Sudeste.

E aqui encontra-se uma das grandes contradições por trás da conjuntura potiguar, que reforça o caráter insólito da aliança entre católicos e integralistas. Por um lado, foi um dos organizadores da Ação Católica Brasileira, por outro era membro da Ação Integralista Brasileira, contando tanto com o apoio entusiástico de Plínio Salgado quanto com a tolerância de Dom Sebastião Leme.

De acordo com o documento Memórias da ditadura,

Na década de 1930, aproximou-se da luta política da Ação Integralista Brasileira (AIB). Com o tempo, foi percebendo que o integralismo apoiava regimes extremamente violentos, como o fascismo e o nazismo. Quando pessoas importantes resolviam sair do movimento integralista, eram perseguidas e algumas eram mortas. O próprio padre Hélder, após sair do partido, passou a ser perseguido e precisou fugir para não ser mais uma vítima. ${ }^{15}$

14 Disponível em: http://g1.globo.com/pernambuco/noticia/2015/12/dom-helder-camara-poderia-ter-vencido-nobel-da-paz-revela-dossie.html. Acesso em 16/11/2018.

15 Disponível em: http://memoriasdaditadura.org.br/biografias-da-resistencia/ dom-helder-camara/index.html. Acesso em 02/07/2008. 19:50. 
Ainda que de formação anticomunista e avesso aos ideais iluministas apregoados pela Revolução Francesa ${ }^{16}$, Dom Sebastião Leme aceitou tal aproximação, motivado pela falta de desenvolvimento social e político de alguns estados como Ceará, Maranhão e o próprio Rio Grande do Norte. Entretanto, devido à ilegitimidade desta aliança Dom Helder não tardou a romper com os integralistas, tanto pela sua percepção doutrinária e moral, quanto pela instauração do Estado Novo Brasileiro, de caráter fascista, o qual estabeleceu relações convenientemente frágeis com a AIB, ao mesmo tempo em que se fortaleceu do apoio da Igreja. Dom Helder, posteriormente, além de criticar regimes centralizadores, passou a estabelecer aproximações entre o catolicismo e marxismo, por intermédio de sua amizade com Roger Garaudy.

Outra personalidade digna de nota foi o renomado folclorista brasileiro Luís da Câmara Cascudo, também um caso de complexa contradição ideológica. Foi aceito pela AIB do Rio Grande do Norte em decorrência da sua abertura a membros que estavam mais interessados em combater o comunismo, e modernidade taxada de degenerada, do que pela doutrina integralista. Integrante da maçonaria, tradutor de discursos de Mussolini para o português do Brasil, receberia uma comenda católica. O fato que merece ressalva é a de que ao receber a comenda católica supostamente não estaria mais fazendo parte da maçonaria ${ }^{17}$, embora não devesse devolver ou negar as condecorações recebidas por Mussolini. Portanto, para o momento foi possível dizer que, face a proximidade entre integralismo e fascismo, este último era tolerável - mais do que a maçonaria. Suas contribuições n'A Ordem são restritas, embora numerosas

16 Este ponto levanta um questionamento curioso: a primeira edição d'A Ordem - RN data de 14/07/1935. Seria o jornal proselitista católico tão influenciado pela ideologia integralista (a "fórmula brasileira do fascismo", segundo CORTEZ, 2002), que sua primeira edição sairia convenientemente no aniversário da Revolução Francesa?

17 Dados os entraves entre Vaticano e Império Brasileiro, conhecidos como Questão Religiosa, durante o governo de D. Pedro II, o qual, de acordo com uma encíclica papal, membros da maçonaria estariam proibidos de ter relações próximas com a Igreja. 
em outros periódicos, com destaque para um artigo em especial, segundo destaca Cortez.

Em 18 de outubro de 1934, Cascudo publicou o artigo "Integralismo é Cópia?", no qual procura mostrar, em poucas e percucientes palavras que o integralismo era o fascismo brasileiro. Antes, o professor Francisco Veras também afirmou que o integralismo é a fórmula brasileira do fascismo que, onde anos antes, através da revolução feita por Benito Mussolini, tinha tomado o poder na Itália. Hitler já era Chanceler do III Reich alemão, mas ainda não tinha botado as unhas para fora e não se conhecia o caráter perverso e desumano do nazismo. Nessa época, Cascudo escreveu o seguinte:

O Integralismo é Cópia?

"O integralismo não é uma cópia. É a fórmula brasileira do Fascismo. Aceitamos muitas soluções internacionais da doutrina sem perder de vista o elemento nacional onde ela é chamada a operar. [...]" (CORTEZ, 2002. p. 9).

Portanto, ainda que antes do desenrolar dos eventos nefastos da Segunda Guerra e do esclarecimento por meio das vias de fato do nazifascismo, Câmara Cascudo, um dos principais nomes integralistas da época, relaciona integralismo e fascismo de maneira irrevogável, apontando não apenas uma aproximação direta entre A Ordem e o integralismo, mas uma indireta entre o Vaticano e o fascismo. Assim como no caso de Dom Helder Câmara, os desenvolvimentos políticos brasileiros ${ }^{18}$ mudaram o rumo histórico de Luís da Câmara Cascudo, que, ao atuar junto ao Ministério da Educação como eminente folclorista, teve seu passado integralista deixado debaixo do tapete.

18 Tanto o início do Estado Novo Brasileiro quanto a Intentona Integralista e o fechamento da AIB. Neste último aspecto, o encontro dos membros da ex-ANL com os da ex-AIB, no cárcere, deve ter esclarecido definitivamente aos integralistas que o poder de Getúlio Vargas advinha das Forças Armadas e não de correntes políticas. 
Um forte aspecto presente nas páginas d'A Ordem foi a pseudoimparcialidade do jornal, o qual afirma abrir suas páginas para todos os eventos e notas jornalísticas desde que estivessem de acordo com a doutrina cristã, excluindo de seu espaço, portanto, qualquer informação que pudesse servir de divulgação positiva à "ameaça vermelha". Em contrapartida, aceitava a promoção das atividades integralistas, como é possível observar a seguir.

Acção Integralista Brasileira

PROVINCIA DO RIO GRANDE DO NORTE

Celebrando hoje o segundo anniversario de sua fundação nesta capital, a Acção Integralista Brasileira realiza, em regosijo, festas commemorativas.

Por mais bem orientado que nos pareça o movimento integralista, nas suas directrizes doutrinarias, não pode este jornal com elle ter nenhuma ligação, aliás em obediencia aos postulados da Acção Catholica ${ }^{19}$, que nos collocam "fóra e acima dos Partidos".

Isso, contudo, não nos impede de divulgarmos, sem responsabilidade da redacção, as notas que nos forem enviadas pelas autoridades integralistas competentes a respeito da doutrina e das actividades dos camisas-verdes dentro ou fóra do Estado.

Publicamos a seguir, remettido pela Secretaria Provincial de Propaganda, as seguintes

\section{DIRECTRIZES DOUTRINARIAS}

I)- O Integralismo compreende o mundo de forma total, e pretende construir a Sociedade, segundo a hierarchia de seus valores espirituaes e materiaes, de acordo com as leis que regem os seus movimentos e sob a dependencial da realidade primordial, absoluta e suprema, que é Deus. [...] (A ORDEM. 14/07/1935)

19 Ação Católica Brasileira é uma associação civil fundada por Dom Sebastião Leme, em 1935, de acordo com as orientações papais de ampliar a militância católica leiga. Foi extinta em 1966, pela CNBB (Conferência Nacional dos Bispos do Brasil). 
Em seu discurso, A Ordem, orientada pela Ação católica Brasileira, encontra-se "fora e acima dos Partidos", embora, enquanto jornal que é, permite-se receber e publicar notas enviadas pela própria AIB, sem assumir responsabilidade da redação. Além de demonstrar a pseudoimparcialidade, sua posição jornalística é danosa à população que tinha n'A Ordem talvez a única fonte de informações sobre o mundo, promovendo um desserviço ainda maior à imagem da imprensa.

Por consequência, as abordagens relativas ao comunismo e suas ações são carregadas de preconceitos, tal como foi relatado na edição seguinte aos acontecimentos da Intentona Comunista, de 1935:

A ORDEM volta hoje a circular, depois de uma semana de interrupção, motivada pela occupação que os extremistas fizeram, de 24 a 27 ultimos, das suas oficinas.

Os communistas tiveram a ousadia de transformar esta folha em orgão da "Alliança Nacional Libertadora", pretendendo humilhar a população catholica do Estado, que viu o seu jornal transformado, de momento para outro, em centro de irradiação vermelha. Aquelles typos e aquellas machinas, sempre por nós utilizados em defesa de Jesus Christo e de sua Igreja passaram a ser cynicamente empregados, pelos agentes de Moscou, em propaganda do anti-Christo e da lepra marxista, contra os quaes sempre tivemos assestadas as nossas baterias.

Os invasores queimaram a nossa edição de domingo que trazia o EVANGELHO de São Matheus, (24,15-35) referente aos "falsos prophetas que farão prodigios e coisas espantosas, a ponto de seduzirem os proprios escolhidos" "Falsos prophetas", sim, porque veem annunciando um paraizo irreal, na terra, para os operarios e os pequenos. Elles, segundo o mesmo Evangelho, fazem effectivamente, nos primeiros instantes de dominnio, "prodigios e coisas espantosas", distribuindo com os proletarios custosas iguarias, vinhos caros, cedulas e moedas de valor. 
Mas depois... Depois é descoberto o embuste e as mascaras dos hypocritas veem ao chão.

Pobres do operarios que se deixaram iludir, elles que são os "escolhidos", os predilectos de Deus. O paraizo terrestre promettido se esvaiu em fumaças. Adeus tranquilidade. Adeus pão. Adeus terra. Adeus liberdade. (A ORDEM. $1 / 12 / 1935)$.

Os eventos norte-rio-grandenses da Intentona Comunista foram, entre seus focos pelo Brasil, o que mais obteve sucesso. Os insurretos tomaram o poder durante uma semana, derrubaram a Coluna Capitolina (presente diplomático de Mussolini a Natal pelo recebimento de aviadores transoceânicos italianos em solo nacional, mas ainda assim, símbolo de um governo fascista) e utilizaram a infraestrutura disponível, incluídas as instalações do jornal A Ordem, para veicular informações.

Nessa linha de raciocínio esta análise recorre às considerações de Rafael Aguiar:

Aqui se coloca uma característica marcante do discurso do jornal: o uso recorrente de aspas, como recurso de ironia, para indicar o que não se pode ser compreendido de forma direta, havendo um significado equivocado por trás disso, como no caso do uso em "Alliança Nacional Libertadora", em que o jornal questionaria indiretamente os ideais da ANL por meio da suposta ironia presente em seu nome, não sendo esta unânime no território nacional, muito menos libertadora, pois representa o "totalitarismo ateu". (AGUIAR, 2018. p. 121)

Uma das maiores evidências da pseudoimparcialidade pode então ser observada quando não apenas as ideologias, mas a estrutura em si é alvo do que a Congregação Mariana de Moços irá tratar como um sacrilégio, ainda que não tivesse sido vandalizado ou destruído pelos comunistas. Mesmo que fosse um ataque simbólico-ideológico ao jornal e indiretamente à Ação Católica e AIB, o uso da redação e maquinário d'A Ordem provocou revolta sem igual, bem como maior combate ao comunismo após o fim da revolta. 


\section{A ORDEM E SUAS FRENTES DE COMBATE}

O comunismo é tratado enquanto patologia pelo jornal, assim como o era pelos rebeldes franquistas. E de alguma forma ameaçada pela "doença da esquerda" (FALCÃO e REBOUÇAS, 2013), poucas seriam as saídas. No caso da Guerra Civil Espanhola a obliteração de redutos republicanos, como Madri, Barcelona, País Basco, repressão e tortura generalizadas, o terror. No caso potiguar, nenhuma destas prerrogativas poderiam ser jamais aplicadas, com exceção de uma ${ }^{20}$, pois, obviamente, além do processo histórico ser divergente do espanhol o país encontrava-se em processo de concentração de poderes nas mãos de Getúlio Vargas, o que dificultava qualquer disputa política acirrada que pudesse levar a uma guerra civil. Para A Ordem, uma das mais diretas formas de combate seria a vitória nas urnas simbolizada pela Liga Eleitoral Católica. ${ }^{21}$

\section{O povo cristão do Rio Grande do Norte derrototá, nas urnas, communismo ateu e etotalitario A Liga Eleitoral Cátolica inicia, hoje, pela Rádio Educadora de Natal, uma "Tumultuosa a sessão dos japonesps e a Ação Social da Igreja - Grande concentração anti-comunista om}

Aos catolicos do Rio G. do Norte e, em geral, a todos os eleitores de boa vontade, a Junta Diocesana da Liga Eleitoral Catolica recomenda, como dignos dos seus sufragios, os seguintes candidatos que aceitaram, expressamente, os pontos das reivindicações catolicas:

$[\cdots]$

Para a Presidencia da Republica a Liga Eleitoral Catolica renova o aviso de que tanto o Major Brigadeiro Eduardo Gomes como o General Eurico Gaspar Dutra merecem,

20 No caso, do ensino religioso, o qual será tratado em breve.

21 Edição 2994, de 29 de novembro de 1945. Disponível em: http://memoria.bn.br/DocReader/docreader.aspx?bib $=764051 \&$ pesq $=$ Acesso em: 22/02/2018. 
pelos compromissos solenemente assumidos de defender as reivindicações dos catolicos, igualmente os votos dos norte-rio-grandenses.

Não podemos, entretanto, dizer o mesmo do sr Iêdo Fiuza, candidato do Partido Comunista - que a LEC aliás, não chegou a consultar - cujas chapas não devem ser aceitas pelos eleitores incautos.

Chamamos a atenção dos eleitores das Rocas e do Alecrim, advertindo-os do pergido que constituirá para o Brasil a vitoria de um candidato do Partido Comunista, cuja aplicação pratica na Espanha, No mexico, na Russia e no Brasil, em 1935, deixou as mais tristes recordações pela serie de crimes praticados. (A ORDEM. 29/11/1945)

Ainda que as relações entre o pleito eleitoral e a religião católica nem sempre sejam claras o bastante, é possível traçar, desde a Proclamação da República, em 1889, uma tentativa de retomada de poder por parte da comunidade católica representada pelo eleitorado e pressões sobre políticos que, em troca da confiança de seus eleitores ${ }^{22}$, se submetem à agenda ideológica católica, como atuar nas esferas estaduais e federais, especialmente no Poder Legislativo. Para tanto, foi criada a Liga Eleitoral Católica (LEC), em 1932, como meio de selecionar candidatos que estivessem comprometidos com a doutrina cristã, ainda que tal iniciativa ferisse o conceito de laicidade estatal, e para impedir ou minimizar a presença de deputados e senadores de esquerda, especialmente comunistas. Ressalva-se aqui que a LEC não foi um partido político, mas uma massa de eleitores vinculados à Ação Católica Brasileira, difundida nos grandes centros urbanos, porém hegemônica na região Nordeste, em especial na abrangência territorial selecionada pela pesquisa. ${ }^{23}$

\footnotetext{
22 Segundo John Locke, compreende-se que o voto é um depósito de confiança que o eleitor realiza em seu candidato. $\mathrm{Na}$ medida em que essa confiança é mantida, também é o apoio a este governante.

23 Edição 344, de 27 de setembro de 1936. Disponível em: http://memoria.bn.br/DocReader/docreader.aspx?bib=764051\&pesq= Acesso em: 24/02/2018.
} 


\section{A ORDEM

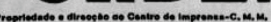

Outra alternativa certeira para o periódico, ainda que a médio e longo prazo, ao combate às ideologias de esquerda foi o ensino religioso. Segundo os editores do jornal e seus contribuintes, o ensino religioso seria uma salvaguarda da próxima geração, criada e nutrida no seio da escola nacionalista cristã contra a suposta perversão moral comunista e o crescimento de doutrinas religiosas não católicas, especialmente não cristãs.

A conquista paulatina de espaço que se consolida na Constituição de 1934 define a presença do ensino religioso nas escolas, foi efeito de constantes pressões da comunidade católica, incluindo-se neste contexto a LEC, sobre o Poder Legislativo, em especial bem recebida pelo Poder Executivo. A aproximação entre Igreja e Governo Vargas era interessante para ambas as partes - por um lado, o combate às doutrinas de esquerda e, por outro, o apoio ao regime que vinha tomando ares centralizadores. Essa questão foi abordada no periódico:

Apposição da imagem de Christo em nossas Escolas Conforme promettemos, damos hoje as solennidades realizadas por occasião da apposição da imagem de Christo nos Grupos Escolares e em outros estabelecimentos desta cidade, na quinta feira ultima.

No Grupo Escolar Izabel Gondim

Após a benção na praça André de Albuquerque, desfilaram os alunos daquelle estabelecimento pela principaes ruas da Cidade Alta e Ribeira, tendo á frente a imagem de Jesus Crucificado, a qual foi carregada pelo paranympho da solenidade, sr. Carlos Gondim.

Á frente do [ilegível] viam-se três meninas symbolisando Fé, Esperança e Caridade. Logo após, seguia a imagem do Crucificado ladeada por uma commissão de alumnos dos 
diversos grupos cursos daquelle Grupo, os quaes empunhavam as bandeiras nacional e pontificia.

[...] Foram entoados hymnos religiosos e civicos. ( $A$ ORDEM, 04/11/1937).

$\mathrm{Na}$ citação os símbolos religiosos e cívicos estão lado a lado, não por motivos pedagógicos, apesar de portados por alunos representando seu grupo escolar, mas por questões proselitistas embutidas na educação dos brasileiros e brasileiras da época. Destaca-se que, a cada vitória educacional católica em âmbito legislativo estadual, A Ordem, em suas páginas, comemorava com amplo entusiasmo o entrelaço dos rituais religiosos e pátrios, como observado na citação anterior.

O jornal chamou atenção ainda para

Uma grande vistoria da consciencia catholica No Rio já se pode ensinar religião nas escolas As instruções do Sr. Francisco Campos RIO, 5 (De avião)-Era bem conhecida em todo o paiz a campanha que moveu contra o ensino religioso o sr. Anisio Teixeira quando director do Departamento de Educação do Districto Federal. [...]

Agora, novos horizontes se abrem á educação, carioca.

O sr. Francisco Campos, secretario da Educação acaba de regulamentar o ensino religioso que já fôra votado pelo Conselho Municipal anno passado.

(A ORDEM, 06/02/1936)

O enfrentamento à laicidade se avolumava na medida em que, com o surgimento da Juventude Brasileira, semelhante ao que se sucedia na Alemanha Nazista e na Itália Fascista, promoveu o patriotismo exacerbado e doutrinador nas escolas.

Nesse sentido, Aguiar explica:

Ao permitir a transmissão de conteúdos religiosos, por meio do projeto proposto pela Juventude Brasileira, a militância católica conquista um forte aliado, pois justamente 
os membros da Congregação Mariana de Moços, a própria Ação Católica, estariam presentes nas fileiras da Juventude para garantir uma maior abrangência do proselitismo católico e sua hegemonia em território nacional. Observa-se que, ainda que aos poucos, a militância cristã busca cada lacuna da relação entre Estado e Igreja para estar presente, e, se possível apropriar-se da condução educacional do país. (AGUIAR, 2018. p. 154)

Tal conjunção de instituições, a partir da criação de um mecanismo complexo de garantia e manutenção do poder doutrinário político e religioso de uma parte da população sobre as demais, é fundamentada em aspectos de promoção do cerceamento de direitos civis e sociais estabelecidos anteriormente na Constituição. Ainda mais preocupante é a observância deste mecanismo sendo reutilizado na atual conjuntura brasileira, levantando uma questão séria para o futuro: como utilizamos o que é aprendido com a história?

\section{CONSIDERAÇÕES FINAIS}

A partir do estudo realizado dentre as mais de 3 mil edições consultadas, catalogadas por temas e outras relevâncias, juntamente com o rico aporte bibliográfico, foi possível identificar várias similaridades do processo histórico da década de 1935 a 1945 com o atual período brasileiro, no que concerne ao endurecimento político, polarização ideológica e os fins dados para a educação, enquanto aparelho ideológico mantenedor da ordem e hierarquia social conservadoras.

Em outras palavras, a Educação é submetida às agendas das políticas públicas de um governo e especialmente utilizada desta forma durante crises sociais, políticas e econômicas, munida de pouca ou nenhuma autonomia para gerir a si mesma e trazer debates entre tendências opostas na busca por um congruente comum.

O jornal A Ordem, de Rio Grande do Norte, em sua riqueza de discurso proveu um material singular de qualidade próxima à narrativa, dada a sua clareza ideológica e redacional. Por meio de sua análise foi possível elaborar uma base sólida referente aos 
eventos da década selecionada, o que permitiu compreender a importância específica do ensino religioso enquanto elemento formativo, para a manutenção da hegemonia cultural e doutrinária católica, bem como do combate ao comunismo. Dessa forma, o estabelecimento desta disciplina privilegiaria a Igreja de tal forma que, assim como atualmente, seria a única com estrutura o bastante para fornecer suporte educacional com profissionais e materiais, sejam eles da Ação Católica Brasileira ou outras entidades, pois é a única que ainda se vale desta iniciativa, a educação formal, para alcançar a população.

O periódico revelou as surpreendentes relações entre doutrinas tão opostas, como o cristianismo e o integralismo, esclarecendo algumas das condições, bem como a ausência de outras, que permitiram a aproximação e apoio mútuo entre as partes, incluindo a tolerância da alta cúpula católica no país. Tanto integralistas quanto católicos buscavam se fortalecer do ultraconservadorismo em ascensão para ocupar espaços políticos determinantes.

\section{REFERÊNCIAS}

AGUIAR, Rafael Henrique Colavite de. Brasil e a espiral histórica: A Ordem, educação e poder. 2018. 166 folhas. Dissertação (Mestrado em Educação) -Escola de Comunicação, Educação e Humanidades da Universidade Metodista de São Paulo, São Bernardo do Campo. 2018.

A ORDEM. Rio Grande do Norte. 1935 - 1945. Edições 001 a 3.020. Disponível em http://memoria.bn.br

ALTHUSSER, Luís. Ideologia e aparelhos ideológicos do estado. São Paulo: Martins Fontes, 1980.

CALDEIRA, João Ricardo de Castro. Integralismo e política regional: a Ação Integralista Brasileira no Maranhão. São Paulo: Annablume, 1999.

CORTEZ, Luiz Gonzaga. Câmara Cascudo, o jornalista integralista. $2^{\mathrm{a}}$ ed. São Paulo: Editora GRD, 2002.

CUNHA, Luiz A. C. R.. "A entronização do ensino religioso na Base Nacional Curricular Comum.” In: Educ. Soc., Campinas , v. 37, n. 134, pp. 266-284, Mar. 2016 . Available from <http://www.scielo.br/scielo.php?script=sci_ arttext\&pid $=$ S0101-73302016000100266\&lng $=$ en\&nrm $=$ iso $>$. access on 18 Apr. 2017. http://dx.doi.org/10.1590/ES0101-73302016158352.

FALCÃO, M. L.; REBOUÇAS, M. N. L. "Velho inimigo: o jornal católico A Ordem e o discurso anticomunista no Rio Grande do Norte." In: Revista Sertões, ISSN: 2179-9040, Mossoró-RN, v.3, n. 1, pp. 33-46, jan./jun. 2013. 
FISCHMANN, Roseli. Estado laico, educação, tolerância e cidania: para uma análise da concordata Brasil-Santa Sé. São Paulo: Factash Editora, 2012. GODOY, Arilda Schmidt. "Pesquisa Qualitativa; tipos fundamentais." In: Revista de Administração de Empresas. São Paulo, v. 35, n.3, pp. 20-29. Mai-Jun 1995. Disponível em: http://www.scielo.br/pdf/rae/v35n3/a04v35n3.pdf GRAHAM, Helen. Guerra Civil Espanhola. Porto Alegre: L\&PM, 2013. KERTZER, David I. O Papa e Mussolini: A conexão secreta entre Pio XI e a ascensão do fascismo da Europa. Rio de Janeiro: Intrínseca, 2017. REBOUÇAS, M. N. L.; FALCÃO, M. L. "Por amor A Ordem: o anticomunismo católico no Rio Grande do Norte (1935-1937).” In: XXVII Simpósio Nacional de História - Conhecimento Histórico e Diálogo Social. Natal $-\mathrm{RN}, 22$ a 26 de Julho, 2013.

SOUZA, Heloisa Helena T. Martins de. "Metodologia qualitativa de pesquisa." In: Educação e Pesquisa, São Paulo, v. 30, n. 2, pp. 289-300, mai.-ago., 2004. Disponível em: http://www.scielo.br/pdf/ep/v30n2/v30n2a07. 